\title{
High-speed train pneumatic braking system with wheel-slide protection device : A modelling application from system design to HIL testing
}

\author{
Lionel Belmon, Chen Liu \\ Global Crown Technology \\ Lanchoumingzuo Plaza, Chaoyangmenwai Avenue, Beijing, China \\ lionel.belmon@globalcrown.com.cn, chenl@globalcrown,com.cn
}

\begin{abstract}
Train pneumatic brakes are part of a train safety system, and are thus critical components. This paper illustrates how modeling can be applied to efficiently design such system, from requirement definition to HIL testing. The valves modeling is discussed along with the system level model. Moreover, in order to study the wheel-slide protection device, a model of the wheel-rail interface has been developed.

The contact model, written in Modelica, has been validated against measurement for different conditions of contact (dry, wet...). The model is fully parametric and allows testing of various adherences.

Finally, the resulting system composed of pneumatic valves, wheel-rail interface and rolling-stock is exported through c-code for integration into a HIL system, providing an efficient test platform for the electronic Brake Control Unit.
\end{abstract}

High speed train; braking ; adherence; pneumatic

\section{Introduction}

High speed train is under major development in China and a lot of interest is put on the design of subsystems. In particular the pneumatic braking system, which is used for instance in emergency braking, is a critical safety system. Much attention and efforts are dedicated to the robustness and reliability of this system, especially regarding its performance for braking distance.

We introduce the main components of the braking system in Figure 1. The compressor system and the emergency circuit have been omitted of the figure.

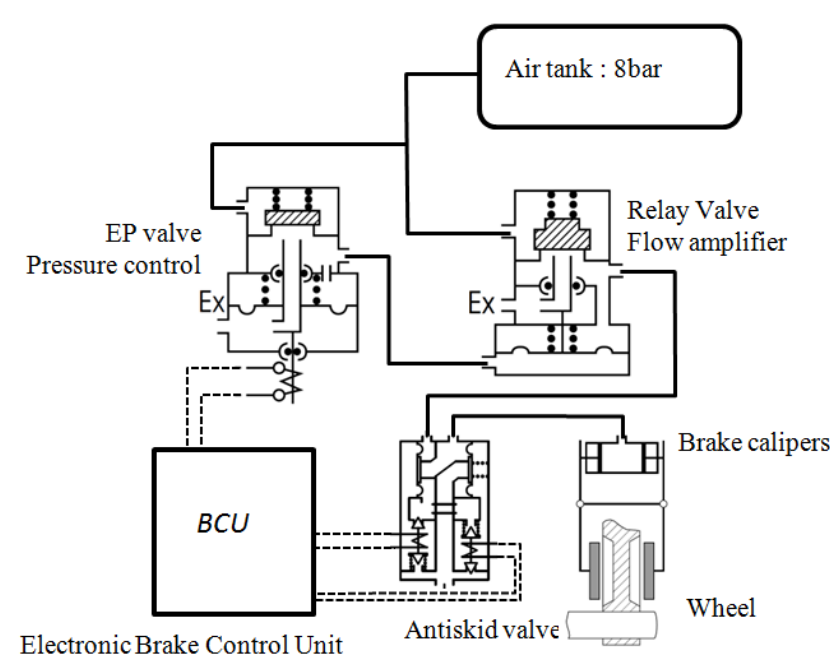

Figure 1 : Simplified schematic of pneumatic brakes [3]

The pressure is supplied by a large air tank. An electro-pneumatic valve (EPV) adjusts the control pressure for the flow amplifier. The flow amplifier valves will work in such a way that the downstream pressure is maintained at the input control pressure. The EPV output pressure is directly controlled by the Brake Control Unit (BCU) and depends on the braking level request.

The Wheel Slide Protection Device (WSP) consists of a set of antiskid valves. These valves are controlled by the BCU in such a way that, when wheel speed is decreasing too fast, the valves modulate brake pressure and prevent wheel blocking.

Besides this basic working principle, an emergency circuit is also available for emergency braking. This circuit has different components and functions but we will focus in this paper on the main braking circuit.

We will now introduce how modeling and simulation supports the design process. We choose the Modelica platform Simulation $X^{\circledR}$ for its convenient 
pneumatic and mechanical libraries. We should also mention the Simulation $X^{\circledR}$ TypeDesigner tool in which has been quite useful in developing new models in Modelica.

\section{Sizing and target pressure}

The first step in the design process is to size the system and define subsystems requirements. The EP brake designer will receive as input requirement a target deceleration at a given speed, as shown in Figure 2.

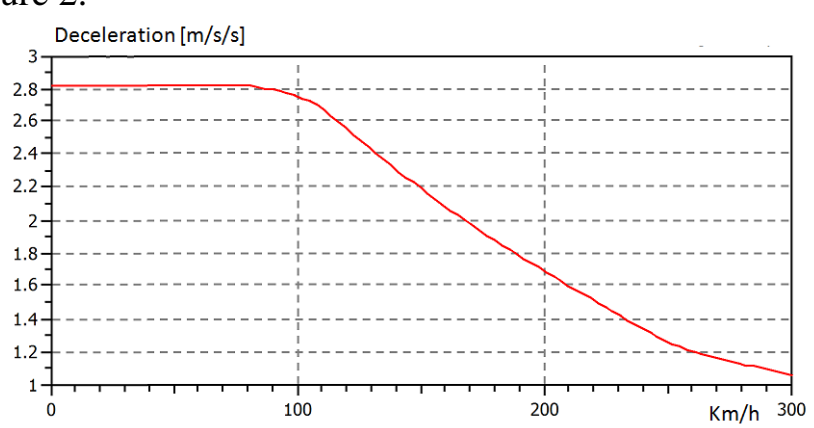

Figure 2 : target train deceleration as a function of speed

The braking force in the train comes partly from the electrodynamic braking but needs to be complemented in certain case by the pneumatic braking system.

Simulation is used at this stage in order to determine the target pressure that the pneumatic brake system should apply to brake cylinders. The model created is a simple model of the rolling-stock, taking into account mass of the cars, rotary inertia of the wheelsets, frictions (aerodynamic...) and electrodynamic brake torque. The brakes model are also simplified but take into account some specific friction effects described later in section 3.4.

The model applies inverse computation in Simulation $X^{\circledR}$ in order to determine a target pressure to reach the requested deceleration as a function of speed.

The process is illustrated in the Figure 3 and some example of results are provided in Figure 4. The effect of the speed-dependent brake friction coefficient can be clearly seen between in the range [0-100] $\mathrm{km} / \mathrm{h}$.

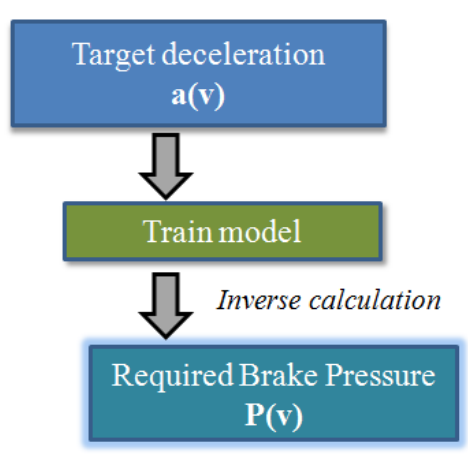

Figure 3 : Target pressure computation

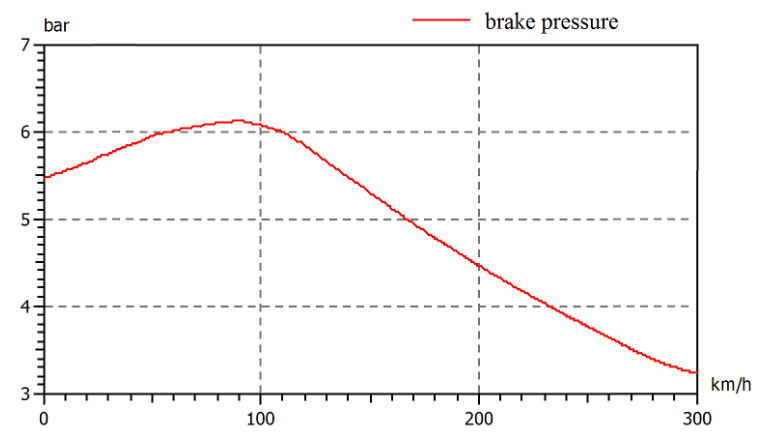

Figure 4 : Computed target brake pressure

The possibility to do inverse computation makes this sizing step smoother and easier to handle.

\section{Components \& Valves modeling}

Once a target pressure is defined as a function of speed and deceleration, detailed design can start. We introduce in this part models that are used by valves designers.

\subsection{Pneumatic model - generalities}

The gas properties for air are considered as ideal gas, this model holds since the system works at pressure below 10 bar, around room temperature.

Volumes are lumped volumes using mass and energy balance to compute the pressure and temperature derivatives in a pretty much conventional fashion.

Flow models for orifices are based on geometrical flow area and a flow coefficient. Sonic flow is accounted for when a given critical pressure ratio is reached.

\subsection{Valve models}

We will only detail the Electro-Pneumatic Valve (EPV) model, other models being similar. We intro- 
duce the basic working principle of the EPV in Figure 5.
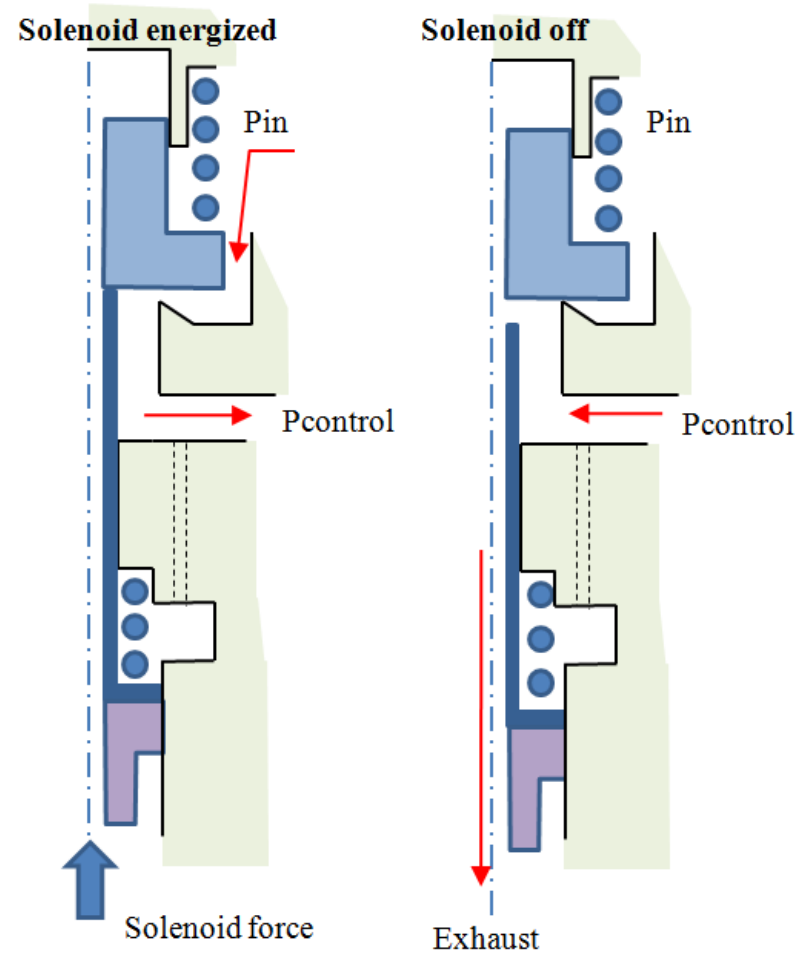

Figure 5 : EPV working principle

The solenoid current is used to adjust the control pressure applied in the brake calipers. The modeling of the solenoid is discussed in the next part.

The model considers 2 moving bodies inside the valve. For each moving body the forces of springs and of pressure areas are taken into account. Sealing friction can also be accounted for but can be usually neglected.

The relative position of each bodies determines the opening of the flow areas of the valve, connecting the inlet pressure to the control pressure or control pressure to exhaust. The variable flow area is defined by an expression for the orifice area as a function of the bodies position. This is achieved through an orifice with time dependent parameter for its area. The time dependent parameters in Simulation $X^{\circledR}$ is quite a convenient feature because of the great flexibility it gives to any component. For a flapper nozzle valve, as found in the EPV, the flow area can be written as :

$$
\mathrm{A}(\mathrm{x})=\pi \mathrm{Dx},
$$

where $\mathrm{D}$ is the seat diameter.

The resulting model structure is provided in Figure 6 . The solenoid model is discussed in the next section.

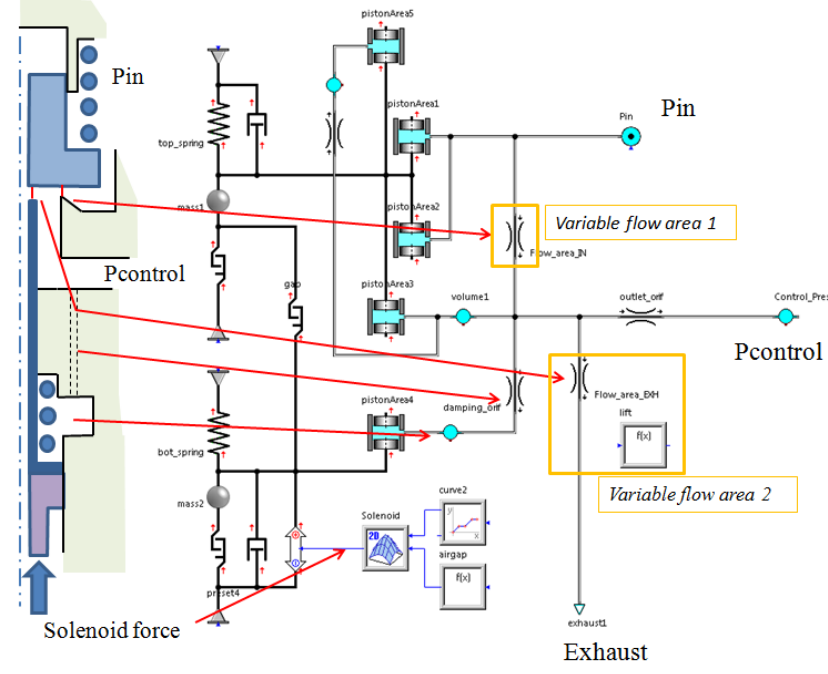

Figure 6 : EVP model structure

For pneumatic valves, it is also common to find designs with membranes. Membranes are modeled as pistons with variable effective area for the pressure force. The effective area is computed from the membrane volume variation by the equation :

$$
\frac{\mathrm{dV}(\mathrm{x})}{\mathrm{dx}}=\mathrm{A}_{\mathrm{eff}}(\mathrm{x}),
$$

Where $\mathrm{V}(\mathrm{x})$ is the membrane volume and $\mathrm{A}_{\text {eff }}$ is the effective area of the piston.

We illustrate, in Figure 7, a key output for the EPV model : the curve giving the control pressure as a function of the current. The curve is computed with a current ramp starting at 0 and going down to 0 , we can notice that the hysteresis of the output pressure is predicted.

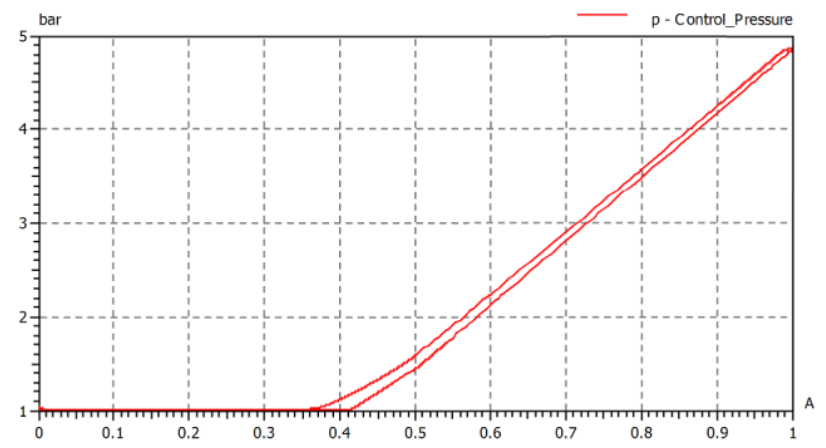

Figure 7 : EPV characteristic curve (Current/Pressure)

The detailed valve model presented helps designers define flow areas, geometries, springs properties, assess valve stability, and assess flow performance along with pressure regulation performance. These models are a key tool to achieve successful designs of such valves. 


\subsection{Solenoid model}

The Solenoid is modeled by the use of a $2 \mathrm{D}$ table giving the force as a function of airgap and current:

$$
\mathrm{F}_{\text {solenoid }}[\mathrm{N}]=\mathrm{f}(\operatorname{airgap}[\mathrm{m}] \text {, current }[\mathrm{A}])
$$

The table is directly implemented into the model described in Figure 8. The data to feed the table can be obtained from experiments or from FEA analysis. A more detailed model, for design purpose of the solenoid, can be done using 1D lumped magenetic element and FEM analysis for the reluctance of airgaps, as shown in Figure 9. It is also possible to include thermal simulation in this part and verify that the solenoid temperature remains in acceptable ranges.

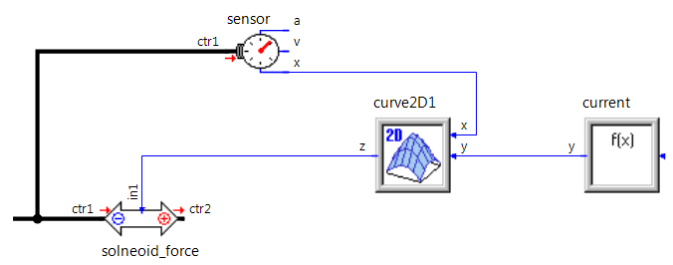

Figure 8 : EPV Solenoid model in SimulationX

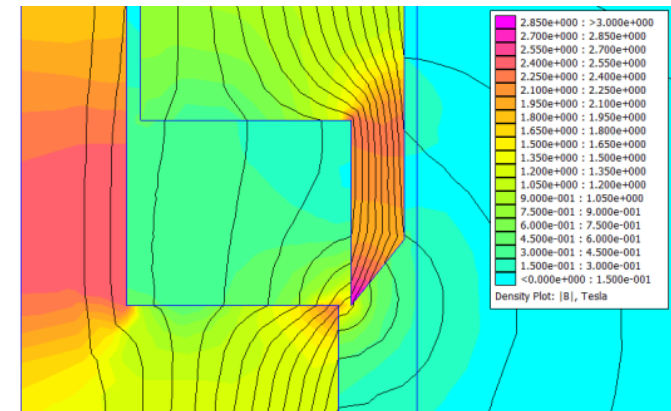

Figure 9 : Detail of a FEM analysis for a solenoid airgap, flux density and flux lines

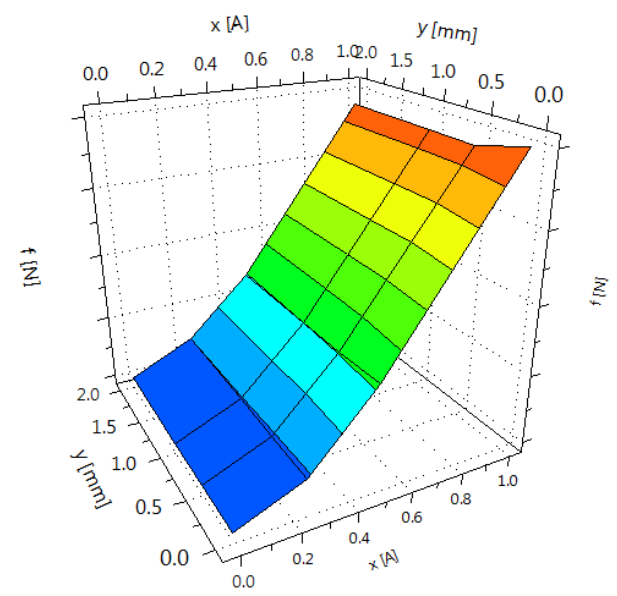

Figure 10 : Solenoid force, as a function of airgap [mm] and current $[\mathrm{N}]$

\subsection{Calipers and brake model}

The calipers mechanical system consists of brake cylinder connected to the brake pads through a lever system, as shown in Figure 12. The corresponding model is shown in Figure 12.

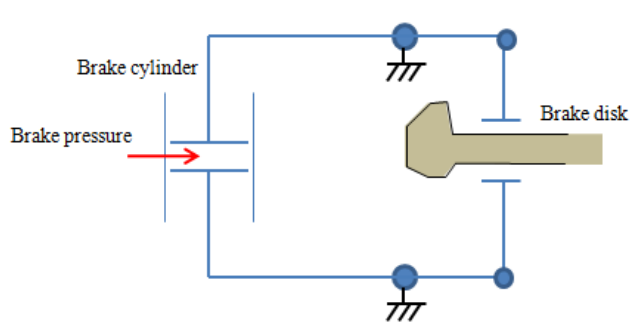

Figure 11 : Schematic of brake caliper

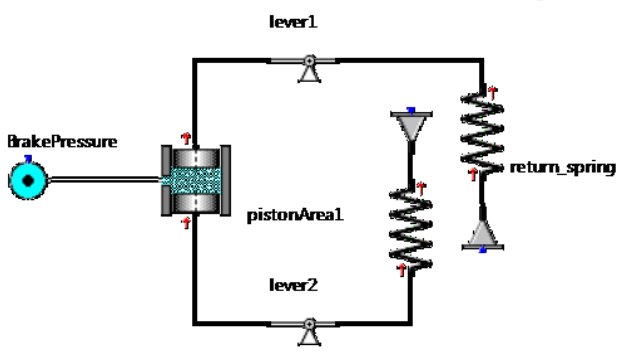

Figure 12 : brake cylinder - brake caliper mechanism For the brake pad contact and brake torque, we use the following equation:

$$
\mathrm{T}[\mathrm{N} . \mathrm{m}]=\mathrm{R}[\mathrm{m}] \lambda_{\text {brake }}(\mathrm{v}) \mathrm{F}_{\text {brake }}[\mathrm{N}],
$$

where $\mathrm{T}$ is the brake torque, $\mathrm{R}$ the mean application radius, $\lambda_{\text {brake }}(v)$ the friction coefficient between the brake pad and the disk, as a function of the relative speed and $\mathrm{F}_{\text {brake }}$ the normal applied on the brake pad and disk. The variable friction coefficient as a function of speed needs also to be taken into account in the initial sizing step (part 2 of this paper) of the braking system, since it will modify the required target pressure.

\section{Wheel-rail interface}

The wheel-rail interface is an important part for simulating the Wheel Slide Protection device (WSP). The role of the WSP is to prevent wheel slide under all conditions. The properties of the rail contact have a major impact on the wheel adherence and on the WSP behavior. For this reason, we need to create a model of the wheel-rail interface.

An important output of the wheel-rail contact model is the creep relationship with creep force. Creep is defined as the relative slip between the wheel and the rail, creep force is the resulting force opposed to the 
direction of motion. Typical curves are provided in Figure 15.

\subsection{Summary of the contact theory}

We introduce in Figure 13 the overall geometry of the rail-wheel contact problem. The Hertz theory is applied and provides a solution for the contact patch between rail and wheel. The contact patch is an ellipse of semi-axes a and b, as shown in Figure 14.
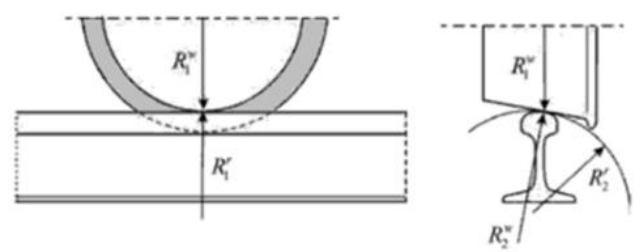

Figure 13 : Wheel-rail geometry

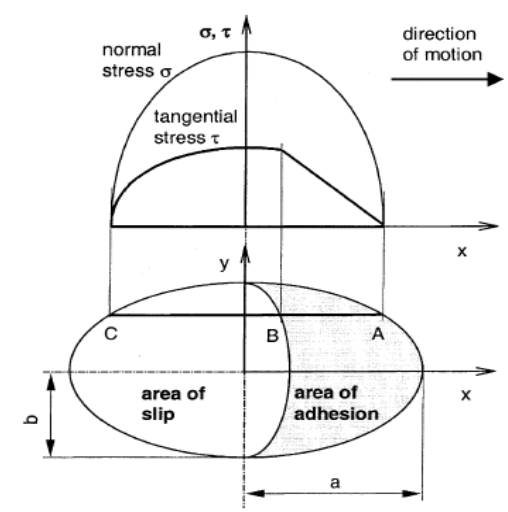

Figure 14 : contact patch geometry

The Hertz theory gives also a formula giving a relation for the semi-axes $a$ and $b$ :

$$
a=f\left(F_{n}, E_{i}, v_{i}, R_{i}\right),
$$

where $F_{n}[N]$ is the normal force, $E_{i}[\mathrm{~Pa}]$ the Young modulus of each body, $v_{i}$ the Poisson ratios and $R_{i}$ the curvature radius at the contact point. The tangential force $F_{X}$ is computed according to the model proposed in [9] which applies Kalker's linear theory and provides :

$$
\begin{gathered}
\mathrm{F}_{\mathrm{x}}=\frac{2 \mathrm{~F}_{\mathrm{y}} \mu}{\pi}\left(\frac{\mathrm{k}_{\mathrm{a}} \epsilon}{1+\left(\mathrm{k}_{\mathrm{a}} \epsilon\right)^{2}}+\arctan \left(\mathrm{k}_{\mathrm{s}} \epsilon\right)\right) \\
\epsilon=\frac{\mathrm{G} \pi \mathrm{ab}}{4 \mathrm{~F}_{\mathrm{y}} \mu} \mathrm{c}_{11},
\end{gathered}
$$

where $\mu$ is a variable friction coefficient computed as :

$$
\mu=\mu_{0}\left[(1-\mathrm{A}) \mathrm{e}^{-\mathrm{B} \omega}+\mathrm{A}\right],
$$

with $\mu_{0}, A, B, k_{a}, k_{s}$ being parameters of the model and $\omega$ being the total creep velocity between rail and wheel.
The proposed creep force model has only 5 parameters that need to be identified on measurement. This model have the advantage of being able to cover accurately small creep and large creep conditions, while being able to account for train velocity and different rail-wheel interface conditions (ice, rain, leaves, dry...).

The main output of interest of the model is the creep force curve, as shown in Figure 15.

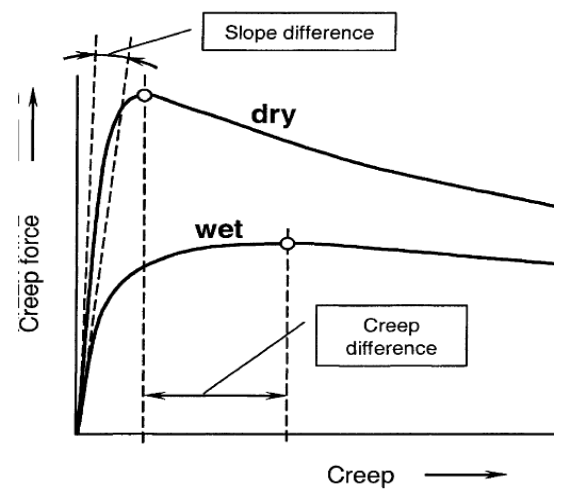

Figure 15 : Classical creep force / creep curves

\subsection{Model implementation in Modelica}

The model proposed described in 4.1 is implemented into Modelica through the help of the TypeDesigner in Simulation $X^{\circledR}$. The model extends a rotary inertia element and represents a wheelset accounting for the wheel-rail interface. We introduce the resulting icon with 1 rotary mechanical connection in Figure 16.

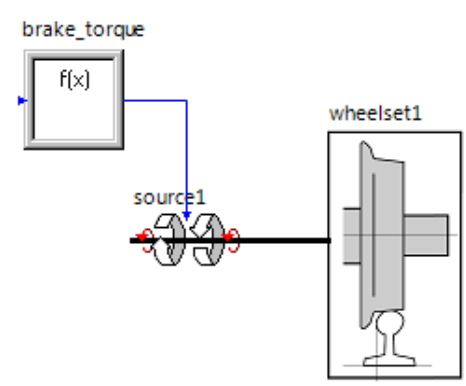

Figure 16 : Wheelset model in Simulation $X^{\circledR}$.

\subsection{Validation of rail-wheel contact model}

Implementation validation and parameters identification of the wheel-rail contact are done using measurements from [9] , [10], [12], [13], [14]. 


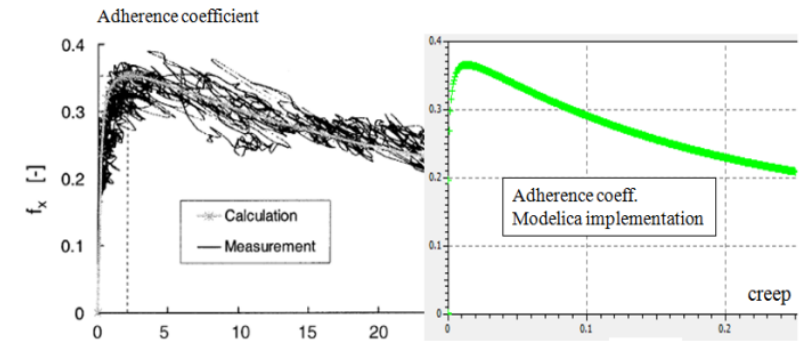

Figure 17 : Comparison of results from [9] with the modelica implementation, Siemens locomotive $S 252$ (dry, v=30km/h)
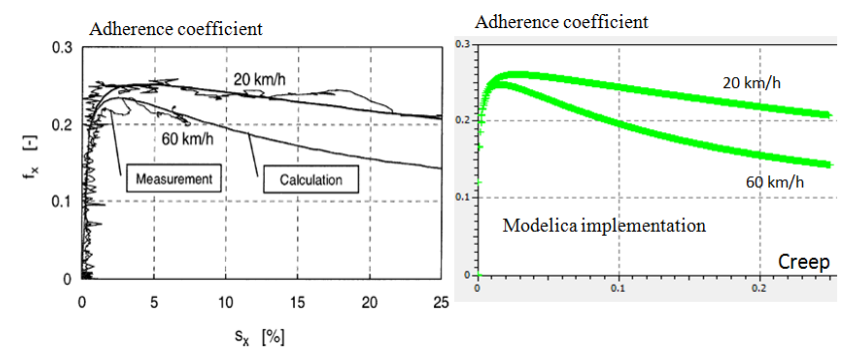

Figure 18 : Comparison of results from [9] with the modelica implementation, Bombardier locomotive $12 \mathrm{X}$ (wet, $V=20$ and $60 \mathrm{~km} / \mathrm{h}$ )

We provide also an example of creep curves for 2 different cars under heavy rain. The front car has a reduced adherence coefficient compared to car in the middle of the train. We illustrate this effect in Figure 19.

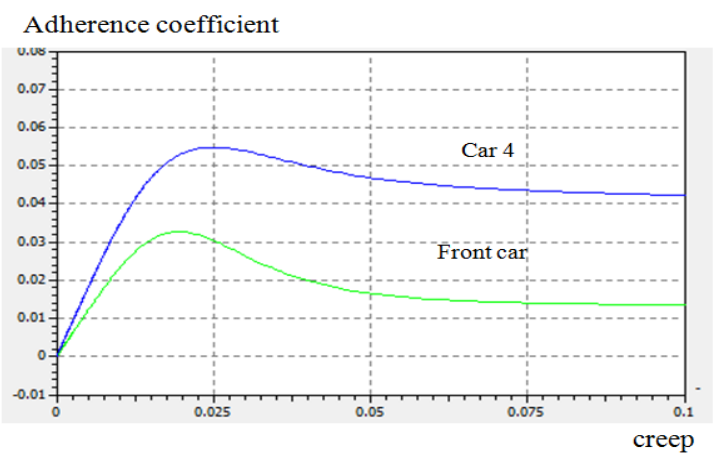

Figure 19 : adherence coefficient at $300 \mathrm{~km} / \mathrm{h}$ under heavy rain, comparison of front car and car 4.

The maximum adherence coefficients provided in Figure 19 are consistent with the measurement on a Japanese Shinkansen from [10], which gives values around 0.02 for the front car and 0.05 for the car 4 .

Overall, parameters for the following conditions were identified :

- Dry - high adherence

- Dry - medium adherence

- Dry - contaminated surface

- Water/rain (multiple cars)

- Oil film

- Fallen leaves residues
The model being parametric, the user can also provide his values for the 5 relevant parameters.

Integrating the wheel-rail contact inside our pneumatic and mechanical model has several advantages over using a full-blown 3D multi-body specialized rail dynamics simulation package. The first advantage is that there is no need for tool couplings or model import/export. The other advantage is that we obtain a very high performance in terms of simulation time, with the possibility to easily integrate our complete model into a HIL simulator.

\section{Wheel Skid Protection device}

With the availability of a predictive wheel-rail contact model, it is possible to perform design and analysis of the Wheel Skid Protection (WSP) device. The device consists of a set of valves piloted by an electronic controller. These valves modulates pressure in order to maintain brake torque but without wheel blocking. Each wheelset is equipped with a WSP, requiring 2 valves by wheelset. One valve is used to close pressure input port, the second valve is used for venting the cylinder to exhaust if necessary. The valves are controlled by the BCU control logic. We show the WSP valve block model in Figure 20.

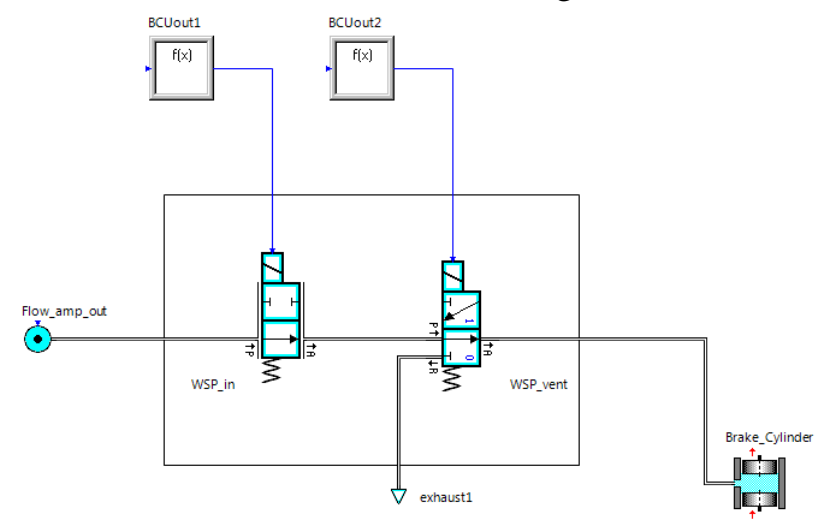

Figure 20 : WSP valve block model structure

We introduce some example of WSP action under heavy rain in Figure 21. 

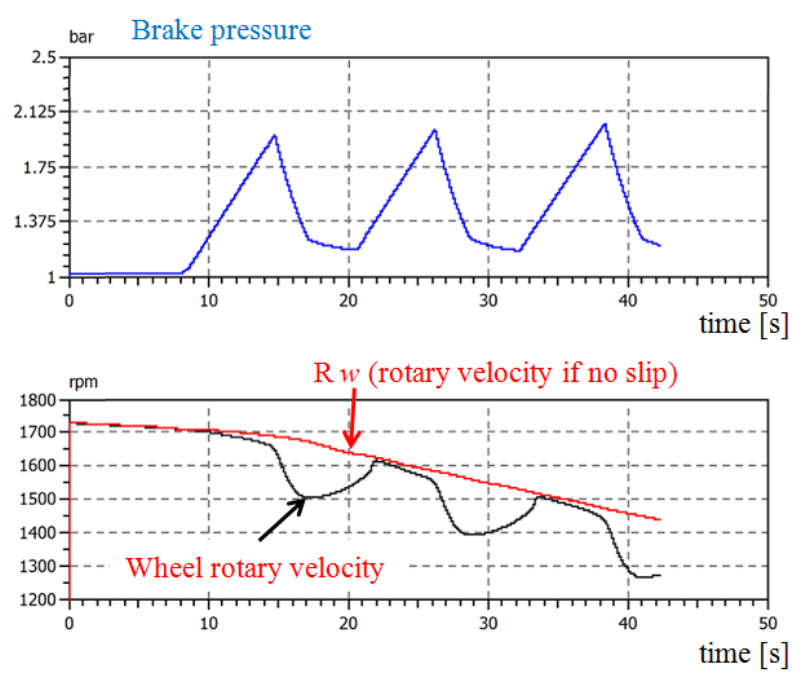

Figure 21 : WSP in action at $300 \mathrm{~km} / \mathrm{h}$ under heavy rain, modulation of brake pressure

The pneumatic model coupled with the wheelset model is used to assess the robustness of the WSP device and optimize the control algorithm, balancing wheel-slide protection and braking distance. The models introduced in this section provide mechanical and control designers with a valuable simulation tool for achieving robust and reliable performance.

\section{Rolling-stock}

The rolling-stock is considered as one mass, or several masses linked together through non-linear spring-dampers. Rolling-stock models needs to account for aerodynamic friction, rolling friction and dry friction. These are implemented as additional forces depending on train velocity.

The system we consider in this article does not use an air-spring load sensing system. If this was the case, a simplified 3D mechanical model of the rolling-stock could be created in order to assess the airspring pressure during braking.

\section{System modeling and HIL simula- tion}

\subsection{System model on the laptop}

The models developed previously are integrated into a system model :

- Compressors and feed lines

- $\quad$ pneumatic tanks, main valves, pipes

- WSP valves

- $\quad$ brakes model

- $\quad$ wheelset with wheel rail contact
- $\quad$ rolling-stock (car)

The system model on the laptop can be used for a MIL (Model In the Loop) step to design the control strategy. It can be used to assess the performance of the Wheel Slide Protection (WSP) device before an actual hardware implementation. The WSP device should insure that the wheel cannot be blocked during braking by modulating the caliper pressure but also maintaining a short braking distance as stipulated by safety regulations $(<3000 \mathrm{~m}$ at $250 \mathrm{~km} / \mathrm{h}$ for instance).

Multiple configurations can be evaluated and tested very efficiently, including fault and failure simulations on a complete train composed of 8 to 16 cars.

\subsection{Real time model}

Besides the need for laptop simulation, it is also possible to use the models to test the controller hardware in a HIL simulator. To achieve this, we need real-time capable models, which will be different than the detailed design models.

The real-time models for components and valves are developed and integrated into a real-time system level model. The model is tested off-line with a fixed step solver and its accuracy is compared with the detailed model developed previously. Numerical stability of the solution is achieved around 1e-3 [s] time step, while maintaining a safe margin for CPU time compared to real-time.

\subsection{C-code export and HIL simulator}

The model can then be exported for the HIL simulator that is used to develop and test the Brake Control Unit. SimulationX c-code export is used. The c-code can be either integrated into a s-function for Simulink and used then for exporting with RTW, but it is also possible to directly export the model for a given real-time target such as a dSpace system, a NI Veristand system or a Cosateq Scale-RT based system. Depending on the cases and requirements, it is possible to interface the input/output cards of the HIL simulator directly inside the SimulationX model, using a I/O boards library.

\section{Conclusions}

A methodology for developing and testing highspeed train pneumatic braking system has been demonstrated. The existing modelica tools have been 
extended with a wheel-rail contact model in order to simulate the wheel-slide protection device.

The proposed tool can then cover needs from sizing and requirements definition, detailed component design down to HIL simulation for control validation and testing.

\section{References}

[1] Analysis of the Braking System of the Korean High-Speed Train Using Real-time Simulations, Chul-Goo Kang, Journal of Mechanical Science and Technology 21, 1048-1057, 2008

[2] Method of Analysis for Determining the Coupler Forces and Longitudinal Motion of a Long Freight Train in Over-the-Road Operation, G. C. Martin, W. W. Hay, Civil Engineering Studies, transportation Series No.2, June 1967

[3] Braking Systems - Railway Technology Today 7, Izumi Hasegawa, Seigo Uchida, Japan Railway \& Transport Review 20, June 1999

[4] Modeling the longitudinal dynamics of long freight trains during the braking phase, Luca Pugi, Duccio Fioravanti, Andrea Rindi, 12th IFToMM World Congress, Besancon (France), June18-21, 2007

[5] Investigation of the dynamics of railway bogies subjected to traction / braking torque, Yunendar Aryo Handoko, Centre for Railway Engineering, Central Queensland University, Australia, Sept. 2006

[6] A Fast Wheel-Rail Forces Calculation Computer Code, Oldrich Polach

[7] Railroad vehicle dynamics: a computational approach, Ahmed A. Shabana, Khaled E. Zaazaa, Hiroyuki Sugiyama, CRC Press, 2008

[8] Modelling and model validation of heavy-haul trains equipped with electronically controlled pneumatic brake systems, M.Chou, X. Xia, C. Kayser, Control Engineering Practice 15, 2007

[9] Creep forces in simulations of traction vehicles running on adhesion limit, O. Polach, Wear 258, 2005

[10] Measurement and analysis of adhesion phenomena in high speed train, Masanobu Nankyo, Shin-ichi Nakazawa, Proceedings of IMECE2008, IMECE2008-66455, 2008
[11] Brake Technology Handbook, Bert Breuer, Karlheinz H. Bill, 2006

[12] Adherence en freinage et anti-enrayeurs, document technique DT257, M.Boiteux, M.Cadier, J.King, W. Kunes, office de recherche et d'essai de l'Union International des Chemins de fer, 1992.

[13] Effect of oil and water mixtures on adhesion in the wheel/rail contact, R. Lewis, E A GallardoHernandez, Proc. ImechE vol 223 Part F, p 275

[14] The "leaves on the line" problem - a study of leaf residue film formation and lubricity under laboratory test conditions, P.M. Cann, Tribology letters, Vol. 24, No2, Nov 2006 